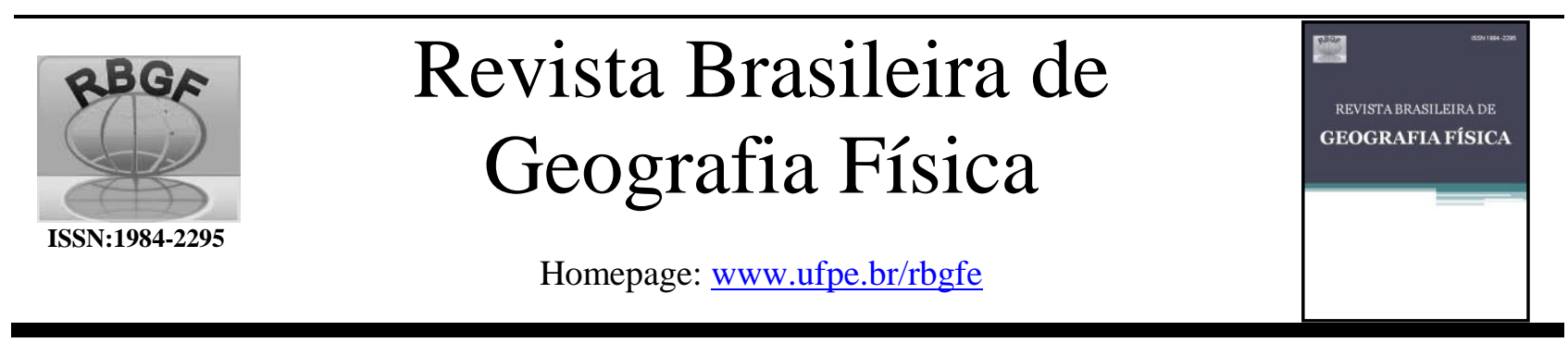

\title{
Aplicação das estimativas de precipitação do Tropical Rainfall Measuring Mission (TRMM) no estudo da pluviometria habitual e excepcional de Goiás e Distrito Federal ${ }^{1}$
}

\author{
Diego Tarley Ferreira Nascimentoํㅗㄴ, Ivanilton José de Oliveira².
}

${ }^{1}$ Dr. em Geografia, Professor da Universidade Estadual de Goiás, Campus Iporá, Rua Serra dos Den, n. 340, Setor Boa Vista, CEP 76200-000, Iporá, Goiás. (64) 3603-1489. diego.tarley@gmail.com (autor correspondente). ${ }^{2}$ Dr. em Geografia, Professor Associado do Instituto de Estudos Socioambientais, Universidade Federal de Goiás, Campus Samambaia, Rua Jacarandá, Qd. D, Prédio do IESA, CEP 74690-970, Goiânia, Goiás. (62) 3521-1170. ivanilton.oliveira@gmail.com

Artigo recebido em 16/05/2018 e aceito em 28/08/2018

\section{RESUMO}

Desde as primeiras imagens de nuvens registradas a partir de abril de 1960 pelo satélite meteorológico TIROS I, diversos parâmetros climáticos têm sido registrados e mensurados por sensoriamento remoto, permitindo o avanço para além da simples observação dos elementos atmosféricos, a ponto de subsidiar complexas análises climáticas. É nesse contexto que se destacam as técnicas de estimativas de precipitação, sob o aporte de satélites, sensores e metodologias distintas. Com o intuito de averiguar a potencialidade de emprego de imagens de sensoriamento remoto na climatologia, o presente estudo objetivou aplicar as estimativas satelitárias de precipitação realizadas pelo Tropical Rainfall Measuring Mission (TRMM) no estudo do regime habitual e excepcional das chuvas no estado de Goiás e Distrito Federal, tendo como base os anos-padrão habitual (2011), seco (2007) e chuvoso (2009). Foram utilizadas as estimativas mensais do TRMM (produto 3B43) para análise da variação espacial e distribuição temporal da precipitação anual, sazonal e mensal entre os três anos supracitados, com o intuito de identificar os limiares dos totais anuais e sazonais e do regime mensal das chuvas na condição habitual e na excepcional (regime seco e chuvoso). Pelos dados apresentados, foi possível constatar distinto padrão das chuvas entre os regimes habitual e excepcional das precipitações no estado de Goiás e no Distrito Federal. Também se verificou que a condição de ano seco, habitual e chuvoso não se refere essencialmente à altura pluviométrica anual, mas, sobretudo, à distribuição das chuvas no decorrer dos meses e à delimitação dos períodos chuvoso e seco. Palavras-chave: Chuvas, estimativas, precipitação, TRMM, anos-padrão.

\section{Application of rainfall estimates of the Tropical Rainfall Measuring Mission (TRMM) in the study of the usual and exceptional rainfall of Goiás and Federal District}

\begin{abstract}
Since the first images of clouds recorded in April 1960 by the TIROS I meteorological satellite, several climatic parameters have been registered and measured by remote sensing, allowing the advancement beyond the simple observation of the atmospheric elements, to the point of subsidizing complex climatic analyzes. It is in this context that the techniques of precipitation estimates are highlighted, with the aid of satellites, sensors and different methodologies. The present study aimed to apply the data generated by the Tropical Rainfall Measuring Mission (TRMM) in the study of the usual and exceptional regime of rainfall in the state of Goiás and the Federal District, in Brazil, in order to investigate the potential of using remote sensing images in climatology, based on the standard years considered as usual (2011), dry (2007) and rainy (2009). The monthly estimates of the TRMM (product 3B43) were used to analyze the spatial variation and temporal distribution of the annual, seasonal and monthly precipitation, between the three years above, in order to identify the annual and seasonal totals thresholds and the monthly rainfall in the usual and exceptional conditions
\end{abstract}

${ }^{1} \mathrm{O}$ presente trabalho é fruto da tese de doutorado defendida pelo primeiro autor, sob orientação do segundo autor, intitulada "Chuvas no estado de Goiás e no Distrito Federal a partir de estimativas por satélite e circulação atmosférica", defendida em 2016 no Programa de Pós-Graduação em Geografia da Universidade Federal de Goiás. 
(dry and rainy regimes). Based on the data presented, it was possible to observe a different pattern of rainfall between the usual and exceptional regimes of precipitation in the state of Goiás and in the Federal District. It has also been found that the condition of dry, usual or rainy year does not refer essentially to the annual rainfall, but mainly to the distribution of rainfall over the months and to the delimitation of rainy and dry periods.

Key words: Rainfall, estimates, precipitation, TRMM, standard years

\section{Introdução}

A aplicação inicial dos satélites meteorológicos se baseava na observação dos deslocamentos dos sistemas frontais e do desenvolvimento dos sistemas locais. Atualmente, a evolução quantitativa e qualitativa dos satélites propicia o fornecimento de dados e informações referentes a distintos parâmetros climáticos, permitindo o avanço para além da simples observação dos parâmetros atmosféricos, a ponto de subsidiar complexas análises climáticas, desde o início sutil de uma seca e seu impacto sobre a vegetação até o monitoramento de fenômenos como El Niño e La Niña ou das mudanças climáticas globais.

Diversos parâmetros climáticos podem ser derivados do sensoriamento remoto, voltados para a atmosfera, oceano e superfície, dentre os quais vale destacar: estimativas de precipitação; pressão atmosférica; balanço de radiação; velocidade e direção do vento; umidade; classificação de nuvens, descargas elétricas; composição de dióxido e monóxido de carbono, metano, ozônio e aerossóis; temperatura da superfície do mar; salinidade da superfície do mar; nível do mar; temperatura da superfície terrestre, índice de vegetação, cobertura de gelo e geleiras; permafrost; albedo; umidade do solo; focos de calor; entre tantos outros.

Desde as primeiras imagens de nuvens registradas a partir de abril de 1960 pelo satélite meteorológico TIROS I, as características de estrutura e de movimento de nuvens foram analisadas de modo a fornecerem importantes insumos à identificação de eventos pluviométricos, tendo como base o comportamento espectral do topo das nuvens. Desde então, várias técnicas de estimativas de precipitação foram desenvolvidas empregando-se satélites, sensores e metodologias distintas, as quais partiram desde a simples indexações de nuvens até a inferência da taxa de precipitação (Liu, 2015).

Atualmente, os principais métodos de estimativa de precipitação por satélite se valem das informações na faixa do visível $(0,3$ a $0,6 \mu \mathrm{m})$, infravermelho $(0,6$ a $14,0 \mu \mathrm{m})$ e micro-ondas (1 $\mathrm{mm}$ e $30 \mathrm{~cm}$ ). No visível, a estimativa de precipitação é feita com base na mensuração do brilho (refletância) do topo das nuvens, que é indicativo de sua espessura e capaz de ser relacionado com a tendência de chuva. No infravermelho, a estimativa é realizada com base na temperatura de brilho do topo das nuvens, que tem relação com sua altura e espessura, e passível de ser traduzida na probabilidade de chuva. Com base nesses pressupostos, diversas técnicas e metodologias foram desenvolvidas para correlacionar o brilho e a temperatura do topo de nuvens com probabilidade de precipitação (Quiroz Jiménez e Collischonn, 2015).

Por sua vez, as estimativas de precipitação baseadas no intervalo do espectro eletromagnético compreendido pelas micro-ondas empregam o registro da emissão termal das gotas de chuva, nas baixas frequências de micro-ondas (10-37Ghz), e a mensuração da dispersão da radiação emitida pela superfície terrestre por conta das partículas de gelo nas nuvens, quando referente às altas frequências (>85Ghz) (Sodré e Rodrigues, 2013).

Kestwall, Joshi e Garia (2014) apontam que os sensores que operam na faixa das microondas são os mais sensíveis à presença de água e/ou cristais de gelo na atmosfera, apresentando a melhor resposta aos processos internos das nuvens e aos mecanismos de formação de precipitação, uma vez que nessa porção do espectro eletromagnético há as menores atenuações.

As técnicas mais recentes para a estimativa de precipitação valem-se de distintas porções da faixa eletromagnética (visível, infravermelho e micro-ondas) e múltiplos sensores, numa proposta denominada de Multi-satellite Precipitation Analysis (TMPA), que permite combinar distintos sensores e diversas faixas espectrais de modo a fornecer melhores estimativas de precipitação (Mantas et al., 2015; Prakash et al., 2016; Darand, Amanollahi e Zandkarimi, 2017).

Os principais satélites disponíveis para estimativas de precipitação o Geostationary 
Operational Environmental Satellite (GOES), o Meteorological Satellite (METEOSAT), o National Oceanic and Atmospheric Administration (NOAA), o Geostationary Meteorological Satellite (GMS), $\quad 0 \quad$ Defense Meteorological Satellite Program (DMSP) e o Tropical Rainfall Measuring Mission (TRMM) sendo esse último detalhado a seguir.

A Missão de Medição das Chuvas nos Trópicos (tradução para Tropical Rainfall Measuring Mission - TRMM) foi lançada em 27 de novembro de 1997 pela National Aeronautics and Space Administration - NASA, em parceria com a Agência Japonesa Aeroespacial Japan Aerospace Exploration Agency - JAXA. O intuito central foi o de monitorar a distribuição temporal e espacial das chuvas, dos sistemas convectivos e das tempestades nos trópicos (NASA, 2016; Huffman e Bolvin, 2017)

As estimativas realizadas pelo TRMM são disponibilizadas pela plataforma de aquisição de dados da NASA, na qual podem ser adquiridos produtos dos diferentes sensores a bordo do satélite em seus formatos originais, processados e disponibilizados na forma de matriz de chuvas na escala de $0,25^{\circ} \times 0,25^{\circ}$, ou provenientes de tratamento climatológico para composição de médias mensais ou anuais de toda a série temporal.

Além disso, podem ser acessados os dados auxiliares, de parâmetro e das estações de superfície, utilizados no programa de validação.

Convém destacar que, para o controle da qualidade das estimativas da precipitação, as informações provenientes do TRMM são calibradas por observações de superfície compreendendo um programa de calibração em campo (Ground Validation - GV) contínuo, que se vale de radares e estações meteorológicas situados em vários pontos na faixa intertropical.
Outro grande diferencial do TRMM é o cruzamento de registros realizados por sensores ativos e passivos, capazes de providenciar mensurações de radiância (VIRS), potência (PR) e temperatura (TMI) que, integradas por diferentes algoritmos e, por vezes, por diversas fontes, são disponibilizadas na forma produtos de estimativas diárias e mensais de precipitação.

\section{Objetivo}

Com o intuito de averiguar a potencialidade de emprego de imagens de sensoriamento remoto na climatologia, o presente estudo tem como objetivo aplicar as estimativas satelitárias de precipitação realizadas pelo Tropical Rainfall Measuring Mission (TRMM) no estudo do regime habitual e excepcional das chuvas no estado de Goiás e Distrito Federal, tendo como base os anos-padrão habitual (2011), seco (2007) e chuvoso (2009).

\section{Localização e breve caracterização da área em estudo}

A área de estudo é representada pelos limites territoriais do estado de Goiás e do Distrito Federal, de forma contígua. Localizada na região central do Brasil, apresenta uma extensão de $345.890 \mathrm{~km}^{2}$, correspondendo a quase $4 \%$ do território nacional (Figura 1).

De acordo com a estimativa realizada para 2017 pelo Instituto Brasileiro de Geografia e Estatística (IBGE), esse território possui uma população total de 9.818 .216 habitantes, dos quais 69\% estão em Goiás (6.778.772) e $31 \%$ no Distrito Federal (3.039.444).

O relevo apresenta média de altitude de $634 \mathrm{~m}$, variando entre $183 \mathrm{~m}$, na depressão do rio Araguaia (no noroeste), e $1.672 \mathrm{~m}$, nos chapadões da região da Chapada dos Veadeiros (no nordeste). 


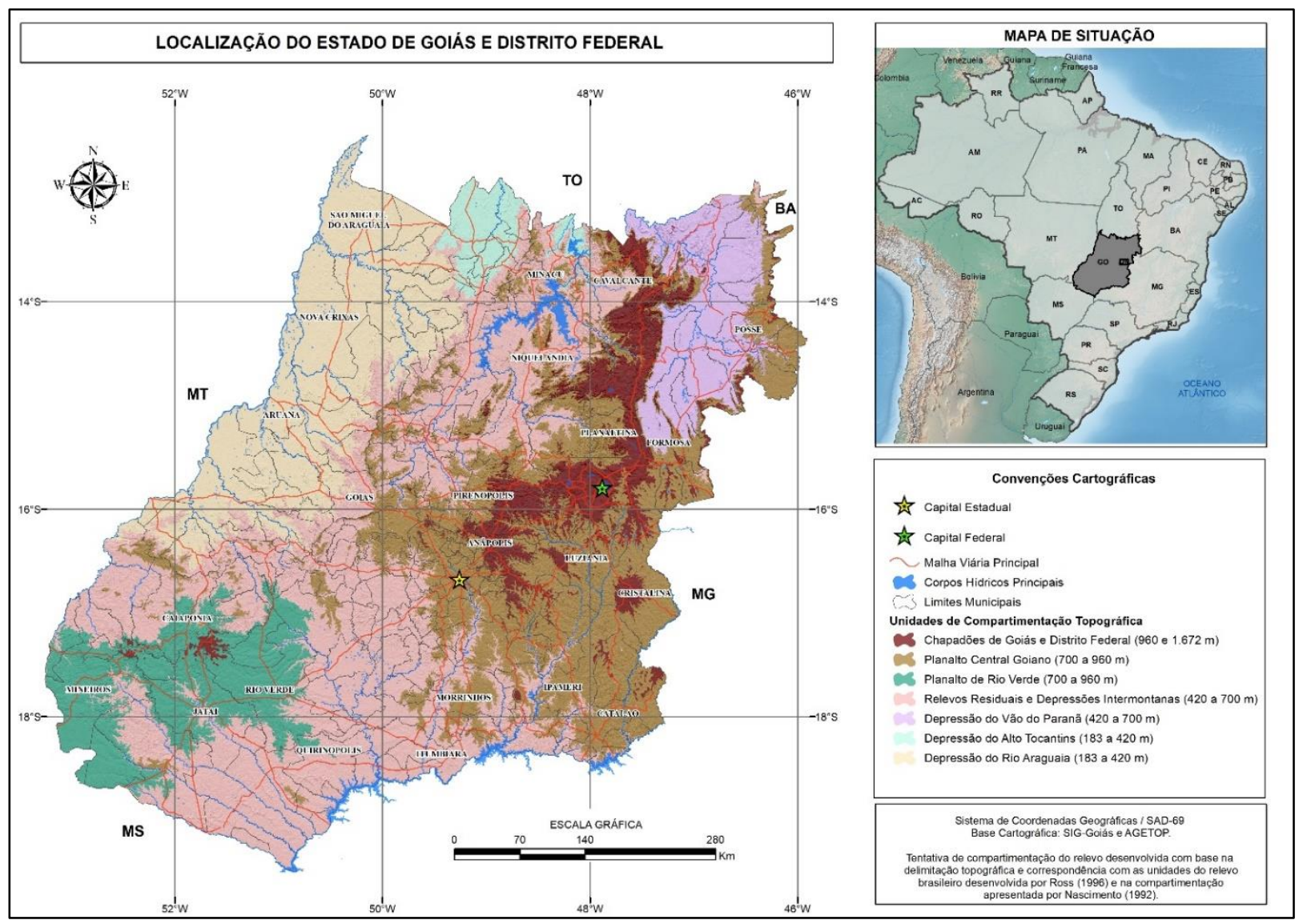

Figura 1 - Localização da área de estudo.

Esse território se destaca por abrigar as nascentes e ser divisor de águas de três importantes bacias hidrográficas do país: Araguaia/Tocantins, Paraná e São Francisco. Além disso, é ainda área core do Cerrado, um bioma de extrema biodiversidade que é representado por um mosaico de formações vegetacionais com fisionomias campestres, savânicas e florestais que apresenta $43,4 \%$ de sua extensão convertida para atividades antrópicas, principalmente na forma de pastagens $(29,4 \%)$ e lavouras $(11,7 \%)$ (Scaramuzza et al., 2017).

Segundo Nascimento, Luiz e Oliveira (2016), a área em estudo compreende o clima Tropical Brasil Central, com o quase predomínio do tipo climático quente e semiúmido, com média de temperatura sempre maior que $18{ }^{\circ} \mathrm{C}$ em todos os meses e ocorrência de 4 a 5 meses secos. Segundo esse autor, a região possui média de precipitação anual variando entre $1.500 \mathrm{e}$ $1.750 \mathrm{~mm}$, com trimestre consecutivo mais chuvoso referente aos meses de dezembro a fevereiro.

Conforme os mesmos autores, $\mathrm{O}$ estado de Goiás e o Distrito Federal experimentam a atuação de massas de ar de origem continental - massa equatorial $(\mathrm{mEc})$ e tropical continental $(\mathrm{mTc})-\mathrm{e}$ marítima - massa tropical atlântica (mTa) e massa polar $(\mathrm{mP})$-, que se deslocam respeitando o caminho preferencial e as barreiras condicionadas pelo relevo e que, de acordo com o aquecimento desigual entre as estações do ano, ora avançam ora recuam sobre a região.

\section{Procedimentos metodológicos}

O estudo da pluviometria desse território foi amparado na análise qualitativa dos recortes amostrais dos regimes habitual e excepcional das chuvas, considerando os anos de 2011 (habitual), 2007 (seco) e 2009 (chuvoso) - anos-padrão indicados para a região por Nascimento, Nunes e Souza Neto (2015).

Foram utilizadas as estimativas mensais do TRMM (produto 3B43) para análise da variação espacial e distribuição temporal da precipitação anual, sazonal e mensal entre os três anos supracitados, com o intuito de identificar a noção dos totais anuais e sazonais e do regime mensal das chuvas na condição habitual e na excepcional (seco e chuvoso).

As estimativas de precipitação foram adquiridas pela homepage <http://mirador.gsfc.nasa.gov/>. Disponibilizadas 
originalmente em formato Hierarchical Data Format (HDF), as imagens foram pré-processadas no software Envi, sendo reprojetadas para o hemisfério Sul, rotacionadas em $270^{\circ}$ e seus pixels foram multiplicados pela quantidade de horas no mês, uma vez que o produto 3B43 corresponde à taxa de precipitação dada $\mathrm{em} \mathrm{mm} /$ hora, sendo, então, convertida para $\mathrm{mm} / \mathrm{mês}$. Por fim, as imagens foram exportadas em formato Geotiff.

Após pré-processadas, as imagens receberam tratamento estatístico com o cruzamento matricial realizado pela ferramenta "band match" do software ArcGIS. Foram calculados os totais anuais e sazonais (períodos seco e chuvoso) de cada um dos três anos-padrão. Considerando a data de início e término das estações do ano, a título de padronização, o período seco foi considerado como sendo o correspondente aos meses de abril a setembro, referentes ao outono- inverno, enquanto o período chuvoso corresponde aos meses de outubro a março, indicativos da primavera-verão.

Vale salientar que, no presente trabalho, não foram realizados testes estatísticos de avaliação dos produtos do TRMM com base em dados de superfície, uma vez que diversos autores averiguaram o desempenho das estimativas do TRMM e encontraram alta correlação com resultados obtidos em estações meteorológicas (Camparotto et al., 2013; Danelichen et al., 2013; Curtarelli et al., 2013; Pereira et al. 2013; Silva, Prela-Pantano e Camargo, 2013, Ochoa et al. 2014; Almeida et al., 2015, Munzimi e Hansen, 2016, Soares, Paz e Picilli, 2016, Anjos, Candeias e Nóbrega, 2016, Quirino et al., 2017, Cerrudo et al, 2017, Louzada, Xavier e Pezzopane, 2018, Cruz et al, 2018, Lelis, Bosquilia e Duarte, 2018).

\section{Resultados e discussão}

Variabilidade anual, sazonal e mensal das chuvas no ano-padrão habitual (2011)

O ano de 2011, empregado como referência ao regime habitual das chuvas, apresentou média zonal de total anual de precipitação de $1.602 \mathrm{~mm}$.

Conforme visto pelo mapa da Figura 2, o total anual de precipitação em 2011 varia entre 1.160 e $2.001 \mathrm{~mm}$ - uma amplitude total de $841 \mathrm{~mm}$. Os menores valores de precipitação são vislumbrados no centro-norte e, principalmente, no nordeste de Goiás, que coincide com a Depressão do Vão do Paranã, área delimitada pelos Chapadões de Goiás e Distrito Federal, que atuam como barreira para o deslocamento e atuação dos sistemas produtores de chuva na região: a $\mathrm{mEc}$, a
ZCAS (Zona de Convergência do Atlântico Sul) e os sistemas frontais associados a mP. Por sua vez, os maiores totais anuais são verificados na faixa que se estende de oeste a sudeste de Goiás correspondente à calha topográfica por onde se deslocam os sistemas produtores de chuvas.

Pela Tabela 1, percebe-se o predomínio de totais anuais de precipitação entre 1.452 e $1.671 \mathrm{~mm}$ - ocupando $43,6 \%$ da área total. Os valores acima desse patamar ocorrem sobre $37,7 \%$ do território, coincidentes com os Relevos Residuais e Depressões Intermontanas, enquanto os valores abaixo de $1.451 \mathrm{~mm}$ representam $18,7 \%$ da área, verificados, principalmente, sobre o Vão do Paranã.

Tabela 1 - Área ocupada pelas classes do total anual de precipitação para o ano-padrão de 2011

\begin{tabular}{crr}
\hline Precipitação $(\mathbf{m m})$ & Área $\left(\mathbf{k m}^{\mathbf{2}}\right)$ & $\mathbf{( \% )}$ \\
\hline 1.160 a 1.231 & 6.971 & 2,0 \\
1.232 a 1.451 & 57.916 & 16,7 \\
1.452 a 1.671 & 150.690 & 43,6 \\
1.672 a 1.892 & 123.341 & 35,7 \\
1.893 a 2.001 & 6.971 & 2,0 \\
Total: & 345.890 & 100,0 \\
\hline
\end{tabular}

Fonte: calculado em SIG.

Ao longo do período chuvoso em 2011, a média zonal de precipitação foi de $1.490 \mathrm{~mm}$. Esse quantitativo se refere a $93 \%$ do precipitado ao longo de todo o ano - evidenciando grande concentração das chuvas. Nesse período, os valores de precipitação variaram, espacialmente, entre 1.067 e $1.869 \mathrm{~mm}$ - uma amplitude de $802 \mathrm{~mm}$. O período chuvoso em 2011 apresentou a mesma variação espacial que o total anual, com menores valores no centro-norte e nordeste, e os maiores verificados numa faixa de oeste a sudeste de Goiás.

No período seco, a média zonal do total de precipitação foi de $111 \mathrm{~mm}$, valor que representa apenas $7 \%$ do total anual de precipitação do ano de 2011. Os valores de precipitação variaram, espacialmente, entre 37 e $288 \mathrm{~mm}$ - uma amplitude de $251 \mathrm{~mm}$, com os maiores valores se concentrando na região sudoeste e os inferiores ocorrendo de forma homogênea em toda a área em estudo.

Os mapas indicados pela Figura 3 e 4 mostram a variação da precipitação mensal do anopadrão habitual de 2011, nos períodos chuvoso e seco, respectivamente, pelos quais se percebe que os meses mais chuvosos foram março, janeiro e dezembro. $\mathrm{O}$ trimestre consecutivo mais chuvoso foi representado por janeiro, fevereiro e março. Por outro lado, julho, agosto e setembro foram os 
meses com menores valores mensais de precipitação, da mesma forma que representaram o trimestre consecutivo mais seco, havendo, inclusive, áreas sem presença de chuva por dois meses.

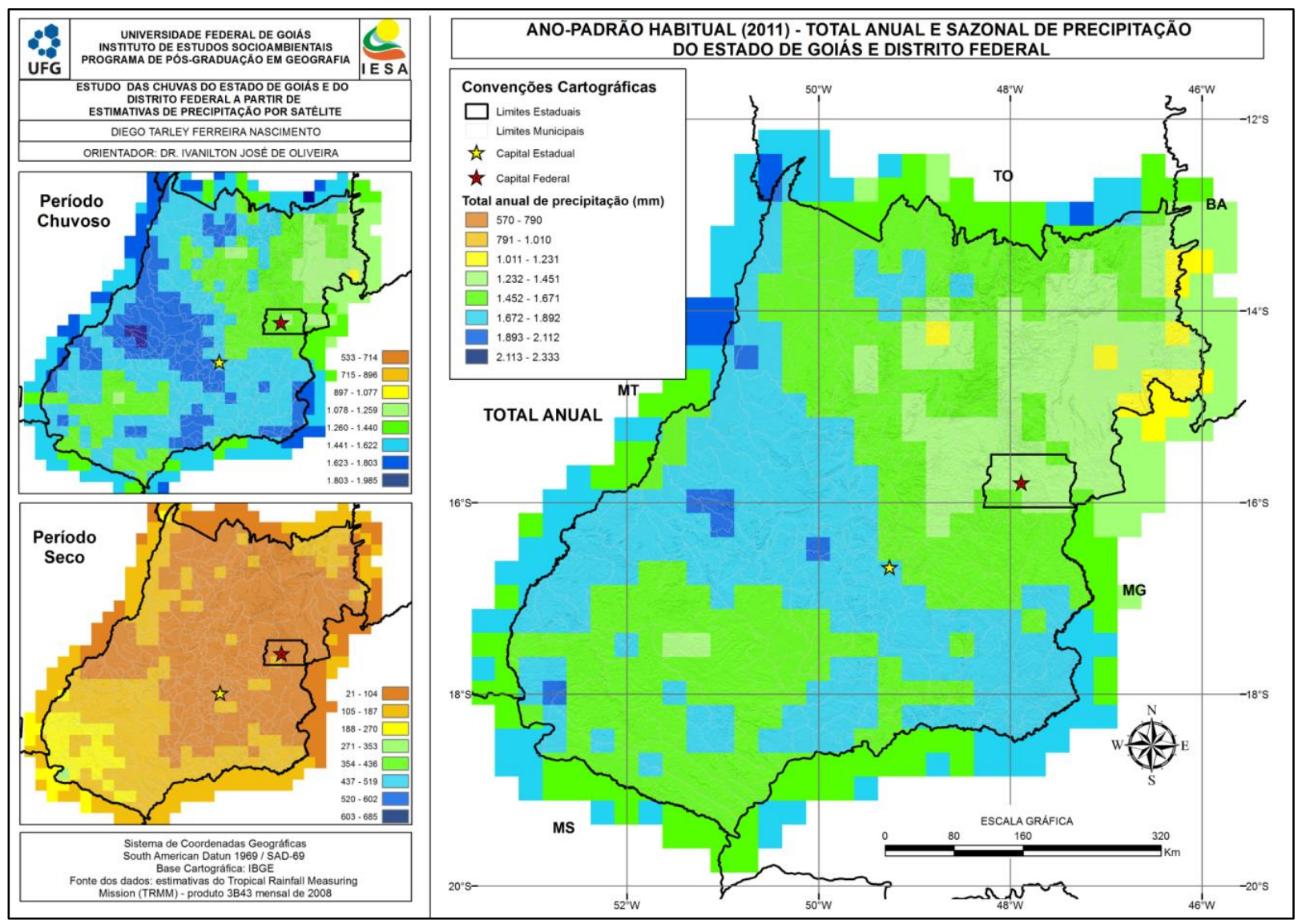

Figura 2 - Ano-padrão habitual (2011): total anual e sazonal de precipitação 


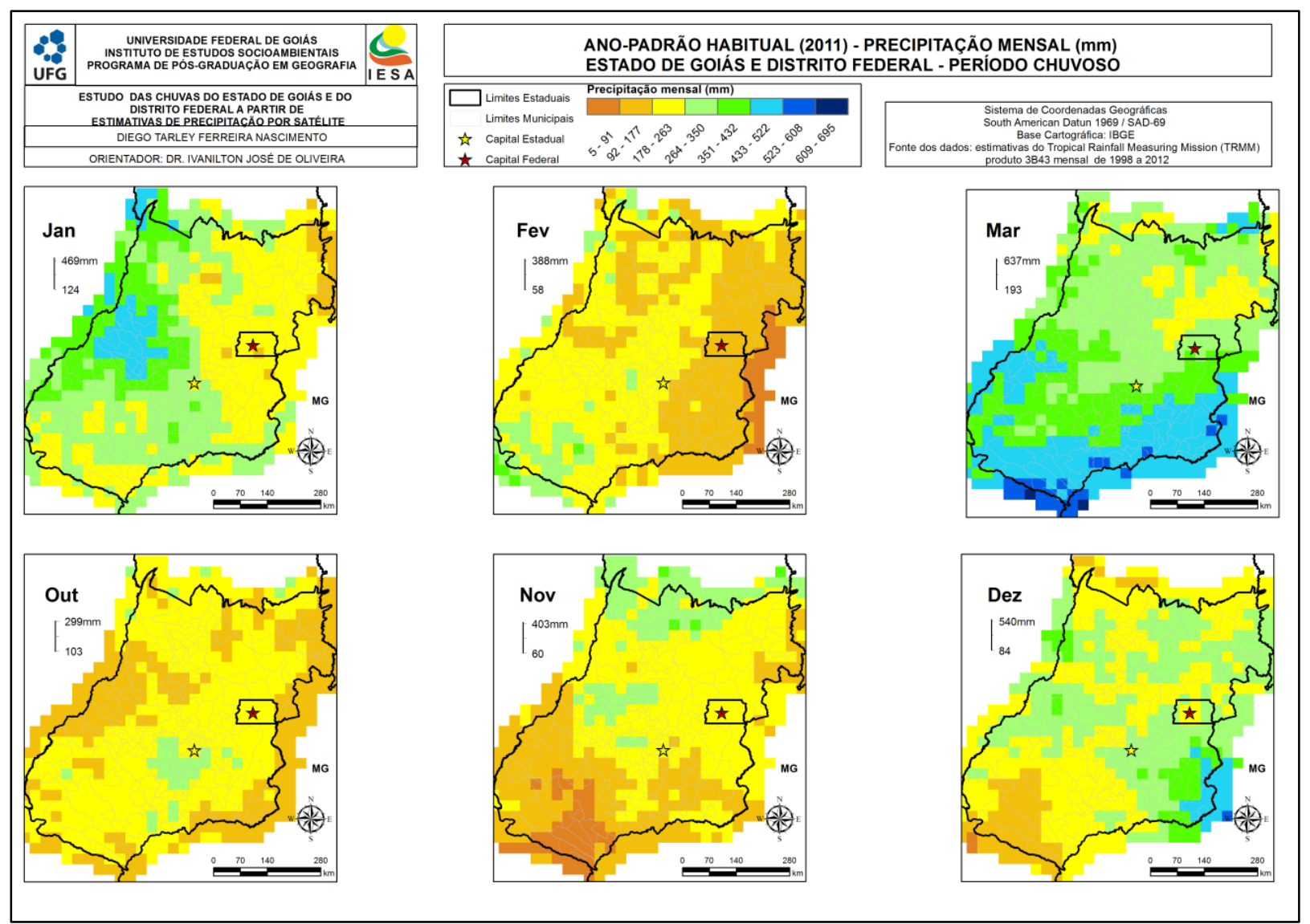

Figura 3 - Ano-padrão habitual (2011): precipitação mensal (mm) durante o período chuvoso

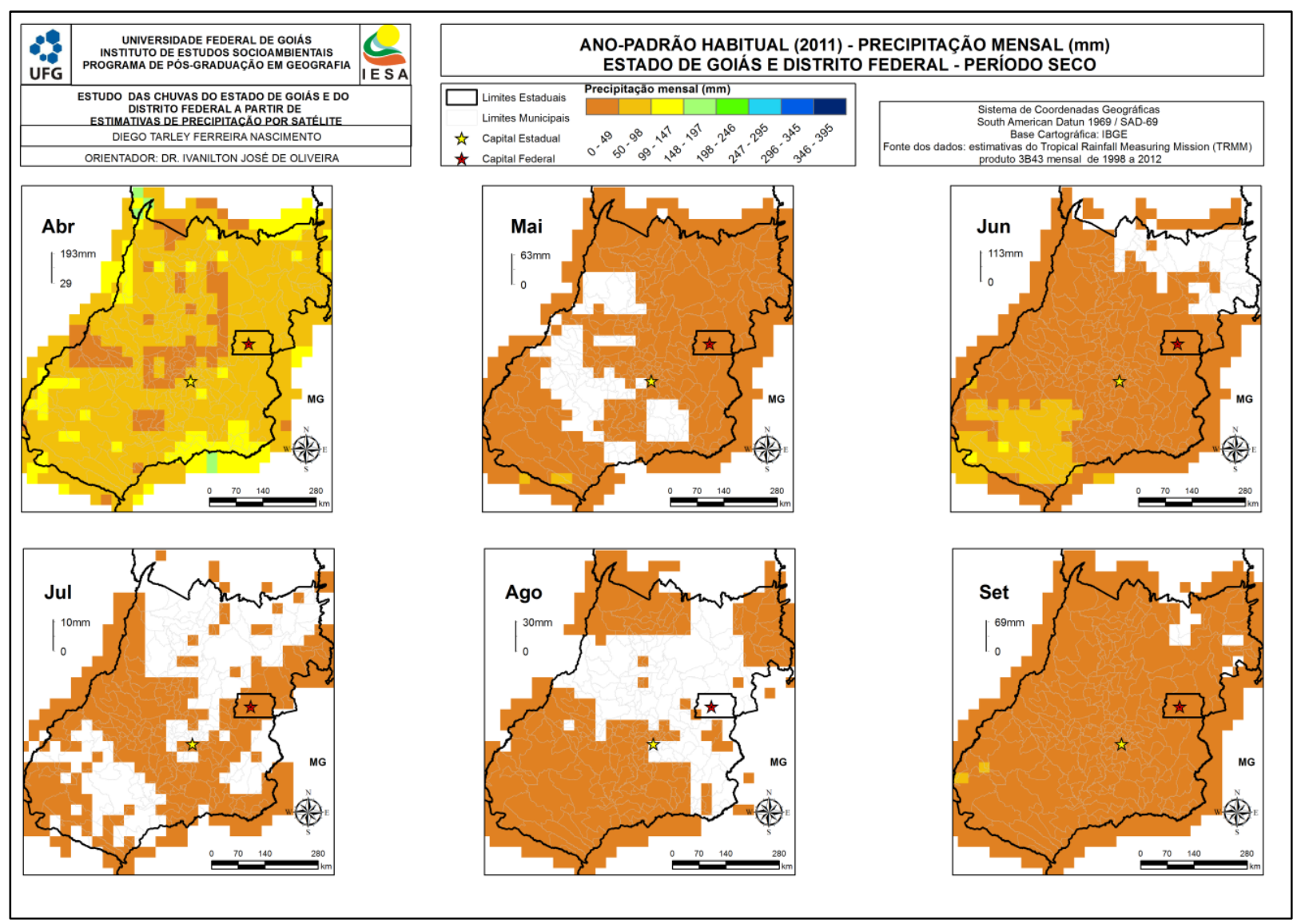

Nascimento, D. T. F., Oliveira, I. J. 
Figura 4 - Ano-padrão habitual (2011): precipitação mensal (mm) durante o período seco

Variabilidade anual, sazonal e mensal das chuvas no ano-padrão seco (2007)

$\mathrm{O}$ ano classificado como padrão seco (2007) apresentou média zonal de $1.188 \mathrm{~mm}$ do total de precipitação. Com relação ao ano-padrão habitual (2011), o total anual de precipitação registrado em 2007 indicou diminuição de 25,8\% (ou $414 \mathrm{~mm}$ ).

Houve considerável variação espacial da precipitação anual em 2007, partindo de $570 \mathrm{~mm}$, no nordeste, e alcançando $1.740 \mathrm{~mm}$, vislumbrado no noroeste, sudoeste e sudeste de Goiás - Figura 5 .

A Tabela 2 indica que predominaram em 2007 os totais anuais variaram entre 1.232 e 1.451 $\mathrm{mm}$, em quase metade da área de estudo $(42,2 \%)$, estando a classe de valores compreendidos entre $1.011 \mathrm{e} 1.231 \mathrm{~mm}$ em segundo lugar quanto à representatividade espacial, com $24 \%$. Os valores inferiores a $1.010 \mathrm{~mm}$ ocorreram sobre 23,1\%, concentrados sobre a região do Vão do Paranã; ao passo que aqueles acima de $1.452 \mathrm{~mm}$ foram verificados em apenas $10,7 \%$ da área, situados no extremo sudoeste e também a noroeste de Goiás.
Tabela 2 - Área ocupada pelas classes do total anual \begin{tabular}{crr}
\multicolumn{4}{c}{ de precipitação para o ano-padrão seco $(2007)$} \\
\hline Precipitação $(\mathbf{m m})$ & Área $\left(\mathbf{k m}^{\mathbf{2}}\right)$ & $\mathbf{( \% )}$ \\
\hline 570 a 790 & 31.103 & 9,0 \\
791 a 1.010 & 48.800 & 14,1 \\
1.011 a 1.231 & 83.121 & 24,0 \\
1.232 a 1.451 & 145.864 & 42,2 \\
1.452 a 1.671 & 32.712 & 9,5 \\
1672 a 1.740 & 4.290 & 1,2 \\
Total & 345.890 & 100,0 \\
\hline
\end{tabular}

Fonte: calculado em SIG.

A média zonal do total de precipitação no período chuvoso de 2007 foi de $1.089 \mathrm{~mm}$, valor que indica uma diminuição de $401 \mathrm{~mm}$ com relação ao ano de 2011 (habitual). A precipitação acumulada no período chuvoso de 2007 correspondeu a $91,6 \%$ do total precipitado nesse ano, proporção ligeiramente abaixo daquela registrada durante o ano habitual, que foi de $93 \%$.

Por sua vez, o período seco apresentou média zonal de precipitação de apenas $99 \mathrm{~mm}$, ligeiramente abaixo do período seco do ano-padrão habitual, que foi de $111 \mathrm{~mm}$. O total precipitado durante o período seco em 2007 representou apenas $8,4 \%$ da precipitação anual. 


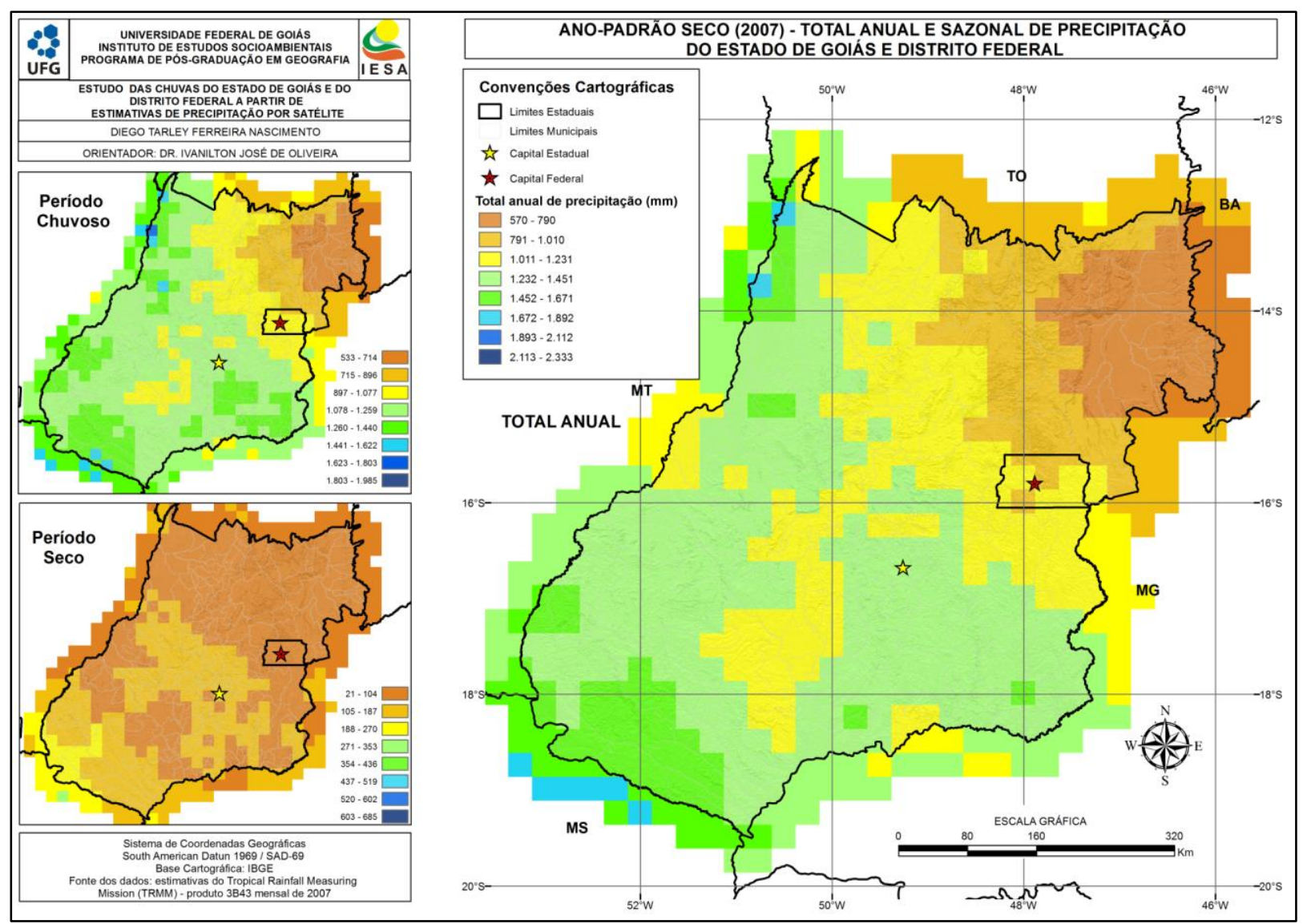

Figura 5 - Ano-padrão seco (2007): total anual e sazonal de precipitação
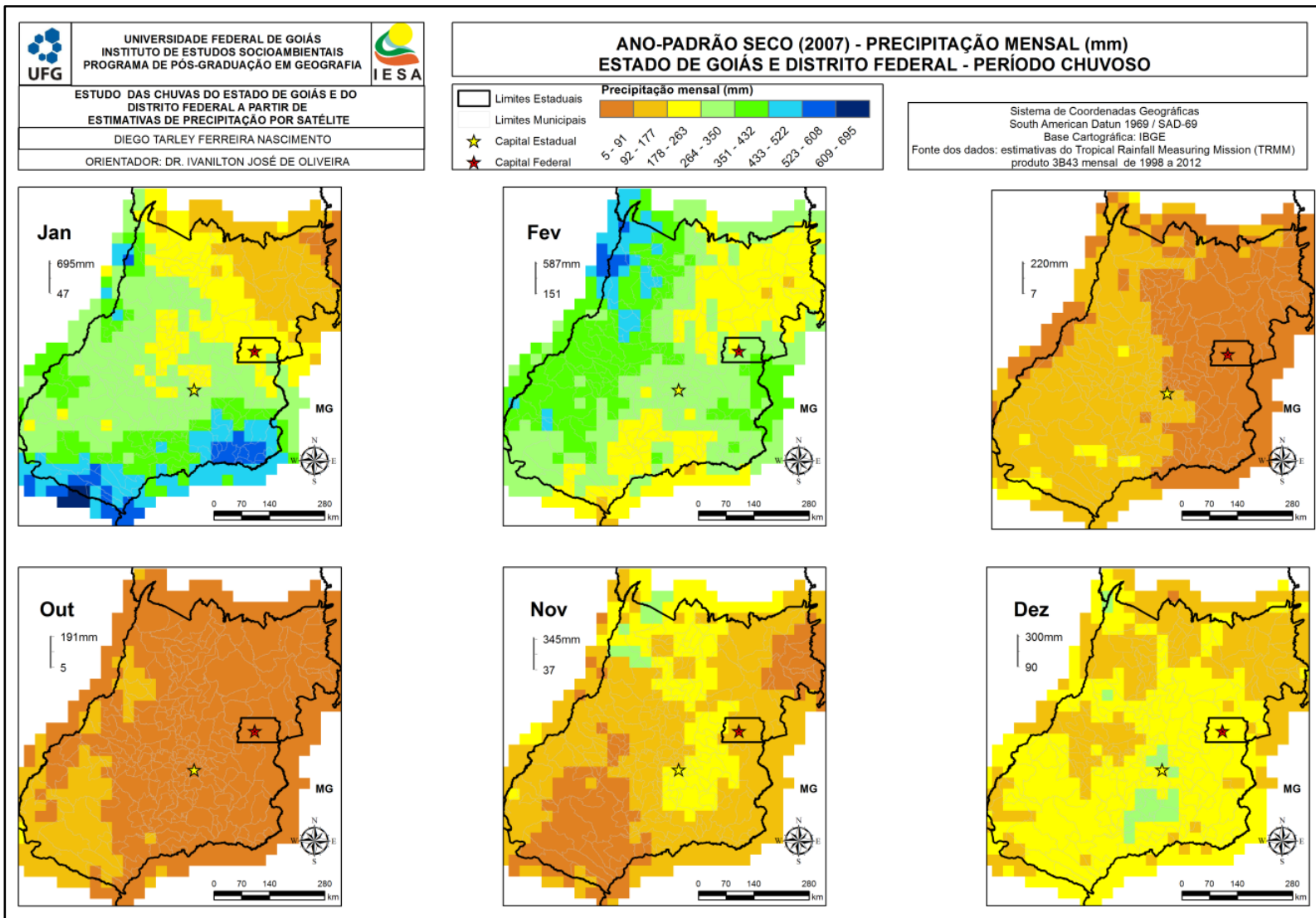
Figura 6 - Ano-padrão seco (2007): precipitação mensal durante o período chuvoso

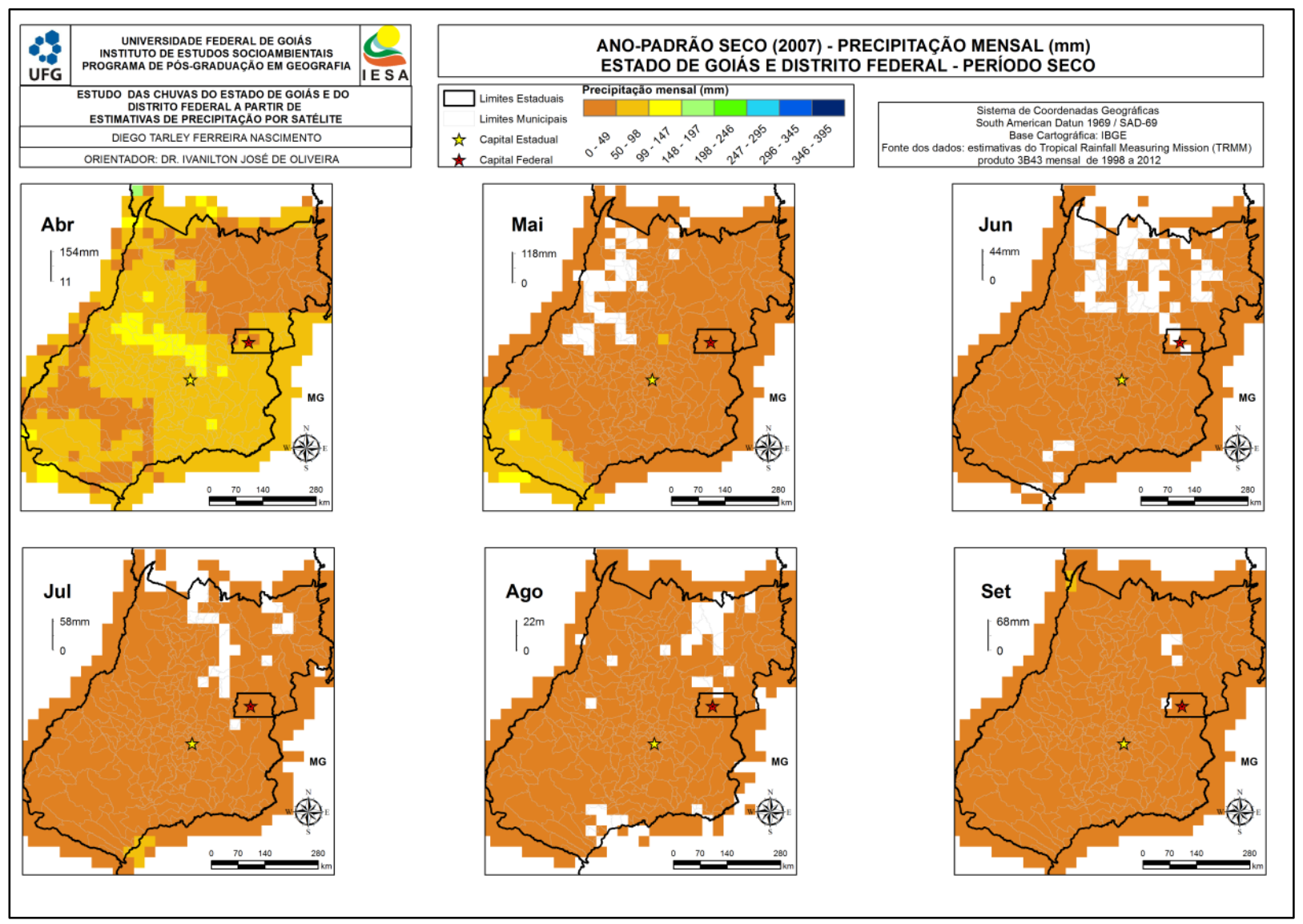

Figura 7 - Ano-padrão seco (2007): precipitação mensal durante o período seco

$\mathrm{Na}$ Figura 5 ainda se encontram representados os mapas do total sazonal de precipitação para os períodos chuvoso e seco de 2007. O padrão espacial do período chuvoso foi razoavelmente semelhante ao da precipitação anual, valendo destacar o menor valor encontrado, de $533 \mathrm{~mm}$, no nordeste de Goiás, e o maior chegando aos $1.702 \mathrm{~mm}$, no sudoeste. Para o período seco, os menores valores chegaram a 21 $\mathrm{mm}$ e predominam por praticamente toda a região nordeste e norte de Goiás, ao passo que os maiores valores de precipitação não ultrapassaram os 274 $\mathrm{mm}$ e se localizaram, principalmente, no sudoeste, mas também no oeste e centro goiano, na calha formada pelos Relevos Residuais e pelas Depressões Intermontanas.

Conforme se constata pelas Figuras 6 e 7 , os meses mais chuvosos em 2007 foram dezembro, janeiro e fevereiro. Por sua vez, os meses com menores acumulados mensais de precipitação foram representados pelo trimestre junho-julhoagosto.
Variabilidade anual, sazonal e mensal das chuvas no ano-padrão chuvoso (2009)

O ano-padrão chuvoso apresentou média zonal do total anual de precipitação de $1.715 \mathrm{~mm}$. Com relação ao regime habitual, o total registrado em 2009 apresentou um incremento de $113 \mathrm{~mm}$ o que representa $7 \%$. Referente ao regime de reduzida pluviosidade, o aumento em 2009 foi de $527 \mathrm{~mm}$, que corresponde a 44,3\% - um incremento considerável das chuvas.

Conforme visto pelo mapa da Figura 8, os menores valores de total anual de precipitação partem dos $1.210 \mathrm{~mm}$, registrados na região do Vão do Paranã, no nordeste de Goiás. Por sua vez, os maiores totais anuais de precipitação chegaram a $2.333 \mathrm{~m}$ e podem ser verificados nas regiões sudoeste e, principalmente, oeste de Goiás - na primeira localidade em razão da atuação do Planalto de Rio Verde, que promove a ascensão dos sistemas atmosféricos advindos do sul (mP), enquanto a segunda se relaciona a influência da Depressão do Rio Araguaia, a qual não demonstra impedimento ao escoamento dos sistemas atmosféricos oriundos do norte $(\mathrm{mEc})$. 
Com relação aos demais anos-padrão, no ano de 2009 houve o predomínio de totais anuais de chuva mais elevados, visto que os valores compreendidos entre 1.452 e $1.892 \mathrm{~mm}$ ocorreram sobre mais de $70 \%$ da área. Merece destaque também a ocorrência considerável das classes acima de $1.893 \mathrm{~mm}$, com 20,9\% (Tabela 3).

Tabela 3 - Área ocupada pelas classes do total anual de precipitação para o ano-padrão de 2009

\begin{tabular}{crr}
\hline Precipitação $(\mathbf{m m})$ & Área $\left(\mathbf{k m}^{\mathbf{2}}\right)$ & $\mathbf{( \% )}$ \\
\hline 1.210 a 1.231 & 536 & 0,2 \\
1.232 a 1.451 & 34.321 & 9,9 \\
1.452 a 1.671 & 111.543 & 32,2 \\
1.672 a 1.892 & 127.094 & 36,7 \\
1.893 a 2.112 & 63.815 & 18,4 \\
2.113 a 2.333 & 8.580 & 2,5 \\
Total & $\mathbf{3 4 5 . 8 9 0}$ & $\mathbf{1 0 0}$ \\
\hline
\end{tabular}

Fonte: calculado em SIG.

Em 2009, a média zonal de precipitação no período chuvoso foi de $1.347 \mathrm{~mm}$. Apesar desse valor ser maior em comparação ao do ano-padrão seco, com relação ao regime habitual ele retratou uma diminuição de 9,5\%, ou seja, $143 \mathrm{~mm}$. Tal condição indica que o padrão chuvoso não foi justificado necessariamente pelo aumento das precipitações na estação mais chuvosa.

A quantidade de precipitação durante o período chuvoso em 2009 correspondeu a 78,6\% do total anual, um pequeno recuo se comparado aos anos-padrão habitual (93\%) e seco (91,6\%).

Por sua vez, durante o período seco, a média zonal de precipitação foi de $366 \mathrm{~mm}$, valor que representou aumento de $255 \mathrm{~mm}$ com relação ao regime habitual e de $267 \mathrm{~mm}$ para o regime seco - elevação de $30 \%$ e $27 \%$, respectivamente traduzindo numa maior quantidade de chuva ao longo dos meses considerados como secos. Portanto, o ano tido como de elevada pluviosidade correspondeu a uma maior quantidade de chuvas e, principalmente, uma melhor distribuição das precipitações ao longo do ano.

$\mathrm{Na}$ Figura 8 ainda consta a variação espacial da precipitação nos períodos chuvoso e seco de 2009, pelos quais é possível perceber que, assim como no caso do total anual, os maiores valores de precipitação ao longo do período chuvoso ocorreram, principalmente, nas regiões oeste e sudoeste de Goiás, alcançando registros de $1.985 \mathrm{~mm}$, enquanto os menores valores se concentraram na região nordeste, partindo de $827 \mathrm{~mm}$.

No período seco, diferente dos demais anos-padrão analisados, os maiores valores de precipitação se situaram na região central e, principalmente, no norte de Goiás, onde o montante de chuva alcançou o máximo de $685 \mathrm{~mm}$; ao passo que os menores valores foram encontrados na região sudoeste, com mínimo de 194 mm. Essa condição supõe uma maior atuação de sistemas atmosféricos produtores de chuva oriundos do Norte do país (mEc e ZCAS) nesse período do ano, uma situação anômala que pode ter resultado no dobro de precipitação ao longo desse período do ano, com relação à média. 


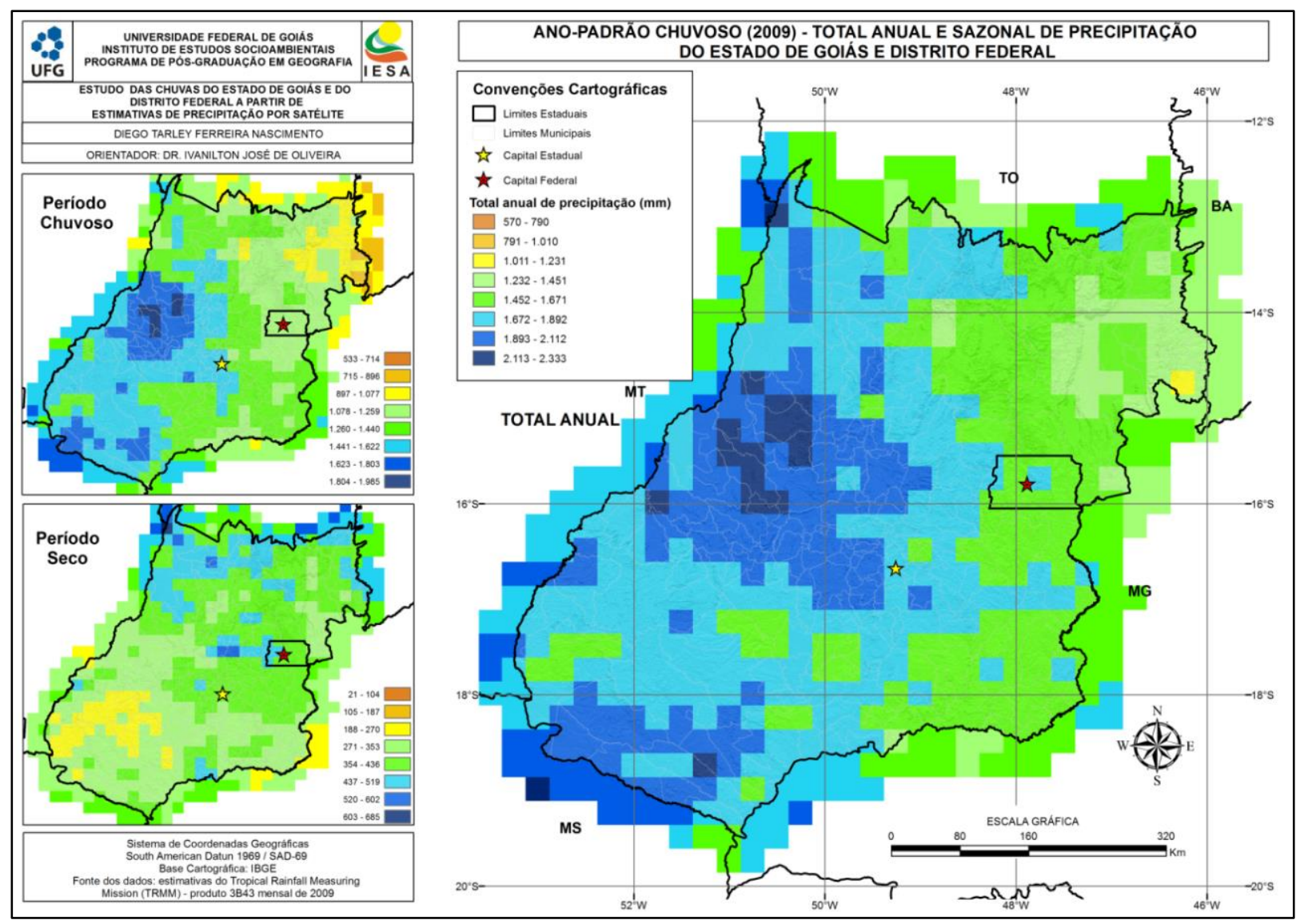

Figura 8 - Ano-padrão chuvoso (2009): total anual e sazonal de precipitação

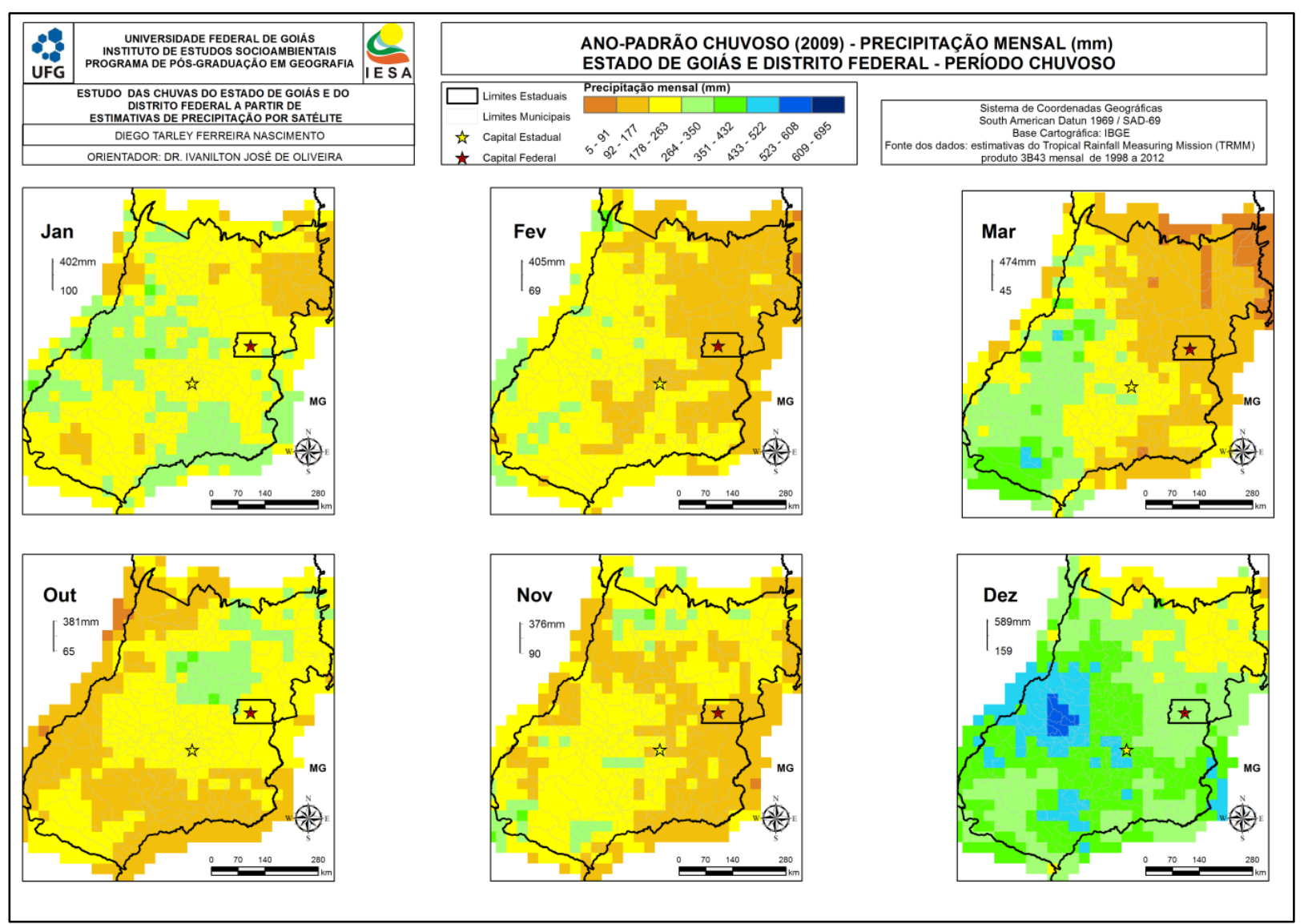


Figura 9 - Ano-padrão chuvoso (2009): precipitação mensal durante o período chuvoso

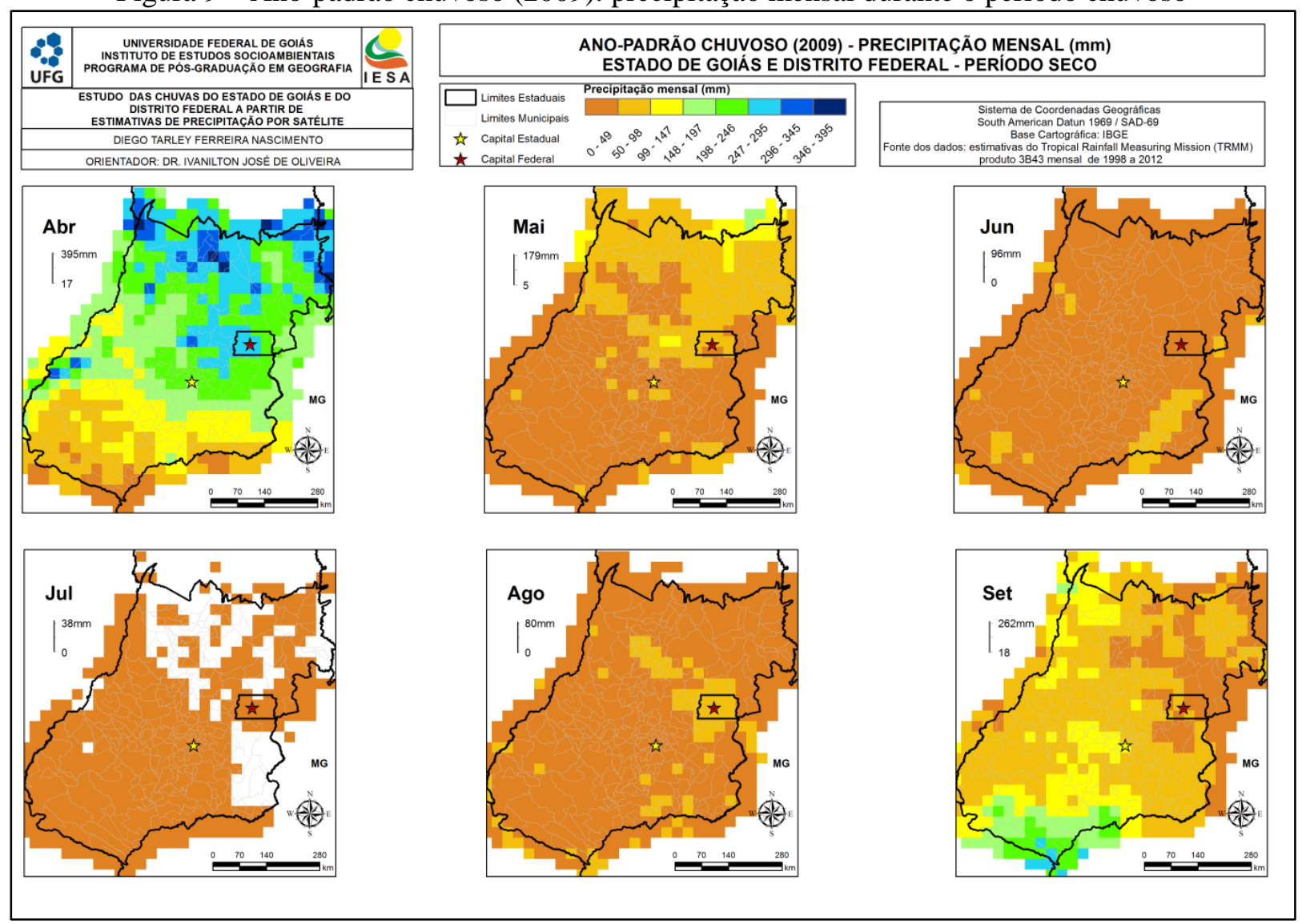

Figura 10 - Ano-padrão chuvoso (2009): precipitação mensal durante o período seco

As Figura 9 e 10 mostram a precipitação ao longo dos meses dos períodos chuvoso e seco do ano-padrão habitual de 2011, respectivamente.

No período chuvoso, os meses de dezembro, janeiro e março foram os que representaram maiores registros de precipitação, sendo o trimestre consecutivo mais chuvoso representado por outubro-novembro-dezembro. Não obstante, os meses com menores acumulados mensais de precipitação corresponderam ao trimestre junho-julho-agosto, com presença de áreas sem ocorrência de chuva, durante o mês completo, apenas em julho. Ainda referente ao período seco, convém destacar a ocorrência de consideráveis valores de precipitação nos meses de abril e setembro, que habitualmente marcam o início e término do período de estiagem, respectivamente.

\section{Considerações Finais}

Valendo-se de recortes amostrais dos anospadrão habitual (2011), seco (2007) e chuvoso (2009), nota-se distinto regime das chuvas entre os regimes habitual e excepcional das precipitações no estado de Goiás e no Distrito Federal. No anopadrão habitual de 2011, a média zonal de precipitação anual foi de $1.602 \mathrm{~mm}$, variando espacialmente na área entre 1.160 e $2.001 \mathrm{~mm}$, com concentração de $93 \%$ das chuvas no período chuvoso. No ano-padrão seco de 2007, a média zonal de precipitação anual foi de $1.188 \mathrm{~mm}$, $414 \mathrm{~mm}$ abaixo do habitual, oscilando espacialmente entre 570 e $1.740 \mathrm{~mm}$, e com maior concentração das chuvas nos meses do período chuvoso (91,6\%). No ano-padrão chuvoso de 2009, a média zonal de precipitação anual foi de $1.715 \mathrm{~mm}$, representando um aumento de $113 \mathrm{~mm}$ em relação ao habitual, com variação espacial de 1.210 a $2.333 \mathrm{~mm}$, e maior distribuição das chuvas ao longo do ano, haja vista a menor concentração das chuvas no período chuvoso $(78,6 \%)$.

$\mathrm{O}$ regime de precipitação entre os diferentes anos-padrão leva a entender que a condição de seco, habitual e chuvoso não se refere essencialmente à altura pluviométrica anual, mas, sobretudo, à distribuição das chuvas no decorrer dos meses e à delimitação dos períodos chuvoso e seco. 
O regime habitual (ano-padrão habitual de 2011) é condicionado por um período chuvoso de seis meses, de outubro a março, e um período seco em cinco meses, de maio a setembro. Interessante ressaltar o fato de que março é o mês que marca o final do período chuvoso para a região, como celebrado na música composta por Tom Jobim, em 1972: "São as águas de março fechando o verão". Dia 19 de março também é marcado como o dia de São José, padroeiro dos agricultores e, segundo a crença católica (cuja origem é desconhecida), caso chova nesse dia, espera-se muita chuva no ano vindouro, garantindo boa safra.

O regime seco (ano-padrão seco de 2007) é expresso pela redução do período chuvoso para quatro meses: janeiro a fevereiro e novembro a dezembro, uma vez que a precipitação verificada em março é reduzida, e condiciona esse mês a representar, juntamente com abril, a transição do período chuvoso para o seco.

Por sua vez, o regime chuvoso (ano-padrão chuvoso de 2009) é justificado pela ampliação do período com chuvas para sete meses, já que o elevado valor de precipitação registrado em abril indicou a inexistência de transição entre o período chuvoso e o seco. Por consequência, nesse regime há a redução do período de estiagem em um mês, passando a corresponder a apenas quatro meses, maio a agosto.

A distribuição espacial da precipitação refletiu bem a influência dos compartimentos topográficos na entrada e no deslocamento, ou mesmo como barreira ao avanço dos sistemas atmosféricos produtores de chuva na região. $\mathrm{O}$ primeiro caso pode ser ilustrado pelos maiores quantitativos de chuvas registrados na Depressão do Rio Araguaia e nos Relevos Residuais, uma vez que a calha topográfica formada por tais compartimentos favorece a entrada e o deslocamento dos sistemas atmosféricos oriundos da Região Norte, responsáveis pelo transporte de umidade da Amazônia. Não obstante, os valores intermediários e inferiores de precipitação se encontraram em áreas em que os Planaltos e Chapadões atuam como barreira à incursão e ao avanço dos sistemas atmosféricos oriundos do norte e do sul, conforme visto na Depressão do Vão do Paranã, que é circundada pelo Planalto Central Goiano e pelos Chapadões de Goiás e Distrito Federal.

Além disso, a variação espacial da precipitação anual mostrou certa relação com a distribuição da cobertura e uso do solo, uma vez que os menores valores de precipitação foram constatados principalmente no nordeste de Goiás, mais especificamente na região da Depressão do Vão do Paranã e bordas dos Chapadões de Goiás e Distrito Federal, área ainda pouco explorada pelas atividades agrícolas e que concentra considerável proporção de remanescentes do bioma Cerrado.

Os maiores valores de precipitação, por sua vez, na maioria das vezes coincidiram com áreas ocupadas por atividades agropastoris, o que sugere que a implantação de tais atividades não tenha ocorrido em resposta apenas à aptidão do solo e adequação à declividade do relevo, mas também à maior disponibilidade de água de origem pluvial sobretudo ao lembrar que a implantação da agricultura irrigada é algo relativamente recente na agricultura goiana.

Os maiores quantitativos de chuva também corresponderam com áreas que apresentam ocorrência de fragmentos de formação florestal, principalmente na Depressão do Rio Araguaia, com fitofisionomias que dependem de grande disponibilidade de água para sua manutenção.

Essa associação dos tipos de formação vegetacional e usos antrópicos às áreas com maior ou menor registro de precipitação corrobora a influência desse elemento climático na organização e na produção dos espaços e das atividades humanas.

\section{Agradecimentos}

Os autores agradecem ao Programa de PósGraduação em Geografia da UFG pela infraestrutura e recursos humanos fornecidos para o desenvolvimento da tese de doutorado da qual se origina este trabalho. E também agradecem ao Conselho Nacional de Desenvolvimento Científico e Tecnológico (CNPq), pela concessão de bolsa de pós-graduação ao primeiro autor durante a realização de seu doutoramento.

\section{Referências}

Almeida, C.T., Delgado, R.C., Oliveira Júnior, J.F., Gois, G, Cavalcanti, A.S., 2015. Avaliação das Estimativas de Precipitação do Produto 3B43-TRMM do Estado do Amazonas. Floresta e Ambiente [online] 22. Disponível: www.scielo.br/pdf/floram/v22n3/2179-8087-

floram-22-3-279.pdf. Acesso: 14 abr. 2018.

Anjos, R.S., Candeias, A.L.B., Nóbrega, R.S., 2016. Caracterização das chuvas através do satélite TRMM em Petrolândia-PE. Revista Brasileira de Climatologia [online] 18. 
Disponível:

https://revistas.ufpr.br/revistaabclima/article/vi ew/44652. Acesso 20 mar. 2018.

Camparotto, L.B., Blain, G.C., Giarolla, A., Adami, M., Camargo, M.B.P., 2013. Validação de dados termopluviométricos obtidos via sensoriamento remoto para o estado de São Paulo. Revista Brasileira de Engenharia Agrícola e Ambiental [online] 17. Disponível: www.scielo.br/pdf/rbeaa/v17n6/v17n6a13.pdf. Acesso: 01 dez. 2017.

Cerrudo, C.G., Díaz, G.M., Juárez, S.H., Ferreira, L.J., 2017. Análisis de la relación espacio temporal entre la precipitación estimada por el satélite TRMM (3B42RT) y el caudal medio diario en la cuenca del Río Iguazú. Meteorologica [online] 42. Disponível: http://www.scielo.org.ar/scielo.php?script=sci arttext\&pid=S1850-468X2017000100003.

Acesso: 02 fev. 2018.

Cruz, M.A.S., Rocha, L.T., Aragão, R., Almeida, A.Q., 2018. Aplicabilidade da Precipitação TRMM para Modelagem Hidrológica em uma Bacia no Agreste do Nordeste Brasileiro. Revista Brasileira de Meteorologia [online] 33. Disponível:

http://www.scielo.br/scielo.php?script=sci_abst ract\&pid=S0102-

$77862018000100057 \& \operatorname{lng}=$ pt\&nrm=iso\&tlng= pt. Acesso: 17 jul. 2018.

Danelichen, V.H.M., Machado, N.G., Souza, M.C., Biudes, M.S., 2013. TRMM satellite performance in estimating rainfall over the midwest region of Brazil. Revista Brasileira de Climatologia [online] 12. Disponível: https://revistas.ufpr.br/revistaabclima/article/vi ew/31203. Acesso: 01 set. 2015.

Darand, M., Amanollahi, J., Zandkarimi, S., 2017. Evaluation of the performance of TRMM Multisatellite Pretation Analysis (TMPA) estimation over Iran. Atmospheric Research [online] 190. Disponível:

https://www.researchgate.net/publication/2577 57782_Comparison_of_PERSIANN_and_V7_ TRMM_multi-

satellite_precipitation_analysis_TMPA_produc ts_with_rain_gauge_data_over_Iran. Acesso: 17 jul. 2018.

Huffman, G.J., Bolvin, D.T., 2017. TRMM and other data precipitation data set documentation. Disponível:
a.gsfc.nasa.gov/pub/trmmdocs/3B42_3B43_do c.pdf. Acesso 01 jan. 2017.

Kestwal, M.C., Joshi, S., Garia, L.S., 2014. Prediction of Rain Attenuation and Impact of Rain in Wave Propagation at Microwave Frequency for Tropical Region (Uttarakhand, India). International Journal of Microwave Science and Technology [online] 2014. Disponível:

https://www.hindawi.com/journals/ijmst/2014/ 958498. Acesso: 17 jul. 2018.

Lelis, L.C.S., Bosquilia, R.W.D., Duarte, S.N., 2018 Assessment of Precipitation Data Generated by GPM and TRMM Satellites. Revista Brasileira de Meteorologia [online] 33. Disponível:

http://www.scielo.br/scielo.php?script=sci_artt ext\&pid=S0102-77862018000100153. Acesso: 17 jul. 2018.

Liu, Z., 2015. Comparison of precipitation estimates between version 7 3-hourly TRMM Multi-satellite Precipitation Analysis (TMPA) near-real-time and research products. Atmospheric Research [online] 153. Disponível:

https://www.sciencedirect.com/science/.../S016 9809514003081. Acesso: 17 jul. 2018.

Louzada, F.L.R.O., Xavier, A.C., Pezzopane, J.E.M., 2018, Climatological water balance with data estimated by Tropical Rainfall Measuring Mission for the Doce River basin. Eng. Agríc [online] 3. Disponível: http://www.scielo.br/scielo.php?script=sci_artt ext\&pid=S0100-69162018000300376. Acesso: 17 jul. 2018.

Mantas, V.M., Liu, Z., Caro, C., Pereira, A.J.S.C., 2015. Validation of TRMM multi-satellite precipitation analysis (TMPA) products in the Peruvian Andes. Atmospheric Research [online] $163 . \quad$ Disponível: https://www.sciencedirect.com/science/.../S016 980951400413X. Acesso: 30 ago. 2016.

Munzimi, Y.A., Hansen, M.C., 2015, Characterizing Congo Basin Rainfall and Climate Using Tropical Rainfall Measuring Mission (TRMM) Satellite Data and Limited Rain Gauge Ground Observations. Journal of applied Meteorology and Climatology [online] 54.

Disponível: 
https://journals.ametsoc.org/doi/abs/10.1175/J AMC-D-14-0052.1. Acesso: 14 set. 2017.

NATIONAL AERONAUTICS AND SPACE ADMINISTRATION (NASA), 2016. Tropical Rainfall Measuring Mission TRMM. Disponível: < https://trmm.gsfc.nasa.gov/>. Acesso: 13 mar. 2016.

Nascimento, D.T.F., Luiz, G.C., Oliveira, I.J., 2016. Panorama dos sistemas de classificação climática e as diferentes tipologias climáticas referentes ao estado de Goiás e ao Distrito Federal (Brasil). Élisée, Rev. Geo. UEG Porangatu [online] 5. Disponível: http://www.revista.ueg.br/index.php/elisee/arti cle/view/5769. Acesso: 17 nov. 2017.

Nascimento, D.T.F., Nunes, L.C., Souza Neto, J.M., 2015. Definição dos anos-padrão para o estudo da pluviometria do estado de Goiás e do Distrito Federal. Brazilian Geographical Journal: geosciences and humanities research medium [online] 6. Disponível: http://www.seer.ufu.br/index.php/braziliangeoj ournal/article/view/28872. Acesso: 13 set. 2017.

Ochoa, A., Pineda, L., Crespo, P., WILLEMS, P., 2014. Evaluation of TRMM 3B42 precipitation estimates and WRF retrospective precipitation simulation over the Pacific-Andean region of Ecuador and Peru. Hydrol. Earth Syst. Sci. [online] 18. Disponível: https://www.hydrolearth-syst-sci.net/18/3179/2014/. Acesso: 30 set. 2017.

Pereira, G., Silva, M.E.S., Moraes, E.C., CARDOZO, F.S., 2013. Avaliação dos dados de precipitação estimados pelo satélite TRMM para o Brasil. Revista Brasileira de Recursos Hídricos [online] 18. Disponível: https://www.abrh.org.br/SGCv3/index.php?PU $\mathrm{B}=1 \& \mathrm{ID}=109 \&$ SUMARIO $=1612$. Acesso: 22 out. 2017.

Prakash, S., Mitra, A. K., Pai, D. S., Aghakouchak, A., 2016. From TRMM to GPM: how wel can heavy rainfall be detected from space? Advances in water resources [online] 88. Disponível: amir.eng.uci.edu/publications/16_AWR_TRM M_GPM.pdf. Acesso: 17 jul. 2018.

Quirino, D.T., Casaroli, D., Oliveira, R.A.J., Mesquita, M., Evangelista, A.W.P., Alves
Júnior, J., 2017. Evaluation of TRMM satellite rainfall estimates (algorithms 3B42 V7 \& RT) over the Santo Antônio county (Goiás, Brazil). Rev. Fac. Nac. Agron. Medellín [online] 70. Disponível:

https://revistas.unal.edu.co/index.php/refame/ar ticle/view/61805. Acesso: 17 jul. 2018.

Quiroz Jiménez, K., Collischonn, W., 2017. Método de combinação de dados de precipitação estimados por satélite e medidos em pluviômetros para a modelagem hidrológica. Revista Brasileira de Recursos Hídricos [online] 20. Disponível: https://www.abrh.org.br/SGCv3/index.php?PU $\mathrm{B}=1 \& \mathrm{ID}=176 \&$ SUMARIO=5041. Acesso: 30 fev. 2018.

Scaramuzza, C.A.deM. Sano, E.E., Adami, M., Bolfe, E.L, Coutinho, A.C., Esquerdo, J.C.D.M., Maurano, L.E.P., Narvaes, I.S., Oliveira Filho, F.J.B., Rosa, R., Silva, E.B., Valeriano, D.M., Victoria, D.C., Bayma, A.P., Oliveira, G.H., Gustavo, B.S., 2017. Land-use and land-cover mapping of the brazilian cerrado based mainly on landsat- 8 satellite images. Revista Brasileira de Cartografia [online] 69. Disponível:

http://www.lsie.unb.br/rbc/index.php/rbc/articl e/view/2065. Acesso: 02 fev. 2018.

Silva, D. F., Prela-Pantano, A., Camargo, M.B.P., 2013. Análise de dados de precipitação estimados pelo satélite TRMM para o Vale do Médio Parapanema - SP. Engenharia na agricultura [online] 21. Disponível: https://reveng.ufv.br/index.php/reveng/article/v iew/353. Acesso: 30 mai. 2017.

Soares, A.S.D., Paz, A.R., Picilli, D.G.A., 2016. Avaliação das estimativas de chuva do satélite TRMM no Estado da Paraíba. Revista Brasileira de Recursos Hídricos [online] 21. Disponível: http://www.scielo.br/scielo.php?pid=S231803312016000200288\&script=sci_abstract\&tln $\mathrm{g}=$ pt. Acesso: 30 nov. 2017.

Sodré, G.R.C.; Rodrigues, L.L.M., 2013. Comparação entre estimativa da precipitação observada pela técnica CMORPH e estações meteorológicas do INMET em diferentes regiões do Brasil. Revista Brasileira de Geografia Física [online] 6. Disponível: https://periodicos.ufpe.br/revistas/rbgfe/article/ view/232961. Acesso: 20 jun. 2017. 